\title{
Quality of life and fear of COVID-19 in 2600 baccalaureate nursing students at five universities: a cross-sectional study
}

\author{
E. G. Beisland ${ }^{1 *}$ (D, K. H. Gjeilo 2,8 , J. R. Andersen ${ }^{1,11}$, O. Bratås ${ }^{2}$, B. Bø ${ }^{3}$, K. Haraldstad ${ }^{4}$, I. H. H. Hjelmeland ${ }^{1}$, \\ M. M. Iversen' ${ }^{1}$, B. Løyland ${ }^{5}$, T. M. Norekvål ${ }^{1,9}$, K. Riiser ${ }^{6}$, G. Rohde $^{4,10}$, K. H. Urstad ${ }^{3}$, I. Utne ${ }^{5}$ and T. N. Flølo ${ }^{5,7}$ on \\ behalf of the LIVSFORSK network
}

\begin{abstract}
Background: The COVID-19 pandemic has caused significant disruptions in the implementation of programs across educational institutions. Nursing students, being both young adults and by practical training, part of the health care system, may be particularly vulnerable during the COVID-19 pandemic. The purpose of this study was to explore the associations between self-reported fear of COVID-19, general health, psychological distress and overall quality of life (QoL) in a sample of Norwegian baccalaureate nursing students compared to reference data.
\end{abstract}

Methods: The survey targeted baccalaureate nursing students from five universities in February 2021. An electronic questionnaire consisted of the Fear of COVID-19 Scale (FCV-19S), the Hopkins Symptom Checklist 5 (SCL-5), one general health and one overall QoL question. The respondents' mean scores were compared to reference data. Hierarchical regression analyses were conducted, and effect sizes (Cohen's d) were evaluated.

Results: In total, 2605 out of 6088 (43\%) students responded. Their FCV-19S scores (mean 2.45, Cl 2.42, 2.48) were significantly higher than those of the reference population (mean 1.8, $P<0.001$ ). Nursing students scores showed significantly lower general health (mean 3.50 0.93 SD, population mean $=3.57$, Cohen's $d=0.07$ ), higher levels of psychological distress (mean 2.68 \pm 1.03 SD, population mean $=2.12$, Cohen's $d=0.55$ ) and lower overall QoL (mean $5.50 \pm 2.16$ SD, population mean $=8.00$, Cohen's $d=1.16$ ) compared to pre-pandemic reference data. FCV-19S scores were significantly associated with levels of general health (Cohen's $d=0.26)$, psychological distress (Cohen's $d=0.76$ ) and overall QoL (Cohen's d=0.18).

Conclusions: Baccalaureate nursing students reported worse outcomes during the Covid-19 pandemic on general health, psychological distress and overall QoL compared to the reference population. Level of fear of Covid-19, however, accounted for few of these differences. Other factors related to the pandemic may have reduced nursing students' overall QoL.

Keywords: Fear of COVID-19, Quality of life, General health, Psychological distress, Nursing students

*Correspondence: ebei@hvl.no

${ }^{1}$ Department of Health and Caring Sciences, Western Norway University of Applied Sciences, Inndalsveien 28, 5063 Kronstad, Bergen, Norway

Full list of author information is available at the end of the article

\section{Introduction}

The coronavirus disease 2019 (COVID-19) pandemic has reached unforeseen dimensions and will have far-reaching implications for quality of life (QoL) into the future [1]. Mental health and QoL have been affected globally, in the general population [1-3], patients and other permits use, sharing, adaptation, distribution and reproduction in any medium or format, as long as you give appropriate credit to the original author(s) and the source, provide a link to the Creative Commons licence, and indicate if changes were made. The images or other third party material in this article are included in the article's Creative Commons licence, unless indicated otherwise in a credit line to the material. If material is not included in the article's Creative Commons licence and your intended use is not permitted by statutory regulation or exceeds the permitted use, you will need to obtain permission directly from the copyright holder. To view a copy of this licence, visit http://creativecommons.org/licenses/by/4.0/. The Creative Commons Public Domain Dedication waiver (http://creativeco mmons.org/publicdomain/zero/1.0/) applies to the data made available in this article, unless otherwise stated in a credit line to the data. 
vulnerable groups $[1,4]$ as well as in health care workers [5-7]. The World Health Organization (WHO) defines QoL as 'an individual's perception of their position in life, in the context of the culture in which they live and in relation to their goals, expectations, standards and concerns' [8]. Mental health may be hampered by concern about one's personal health or by worries about family members and friends, and in the case of health care providers, concern for patients. Furthermore, mental health may be hampered by stress, frustration or annoyance about being restricted as part of precautionary measures, such as prolonged lockdown periods and social distancing and school closures or the use of quarantine [9-11].

Mental health may be challenged in a dual manner during a pandemic among health care providers, as they are exposed to the risk of infection both professionally and in their private lives $[12,13]$. A recent systematic review and meta-analysis reported pooled prevalence estimates of stress, anxiety, depression and sleep disturbances among nurses during the COVID-19 outbreak. More than one third of nurses reported higher scores on these measures than those reported during the previous Middle East Respiratory Syndrome (MERS) and Severe Acute Respiratory Syndrome epidemics [5].

Measures of anxiety and depression using different instruments are generally more prevalent in college students than in the general population as such $[9,14,15]$. In a 2018 nationwide survey of Norwegian students in a higher education setting, their health and psychological distress were studied [16]. A worrisome increase in selfreported psychological distress over recent years was found, as assessed by the Hopkins Symptom Checklist (SCL-25). The scores were markedly higher for women than for men at all time-points [16]. A Norwegian survey of QoL and psychological distress during the COVID-19 pandemic found a general decline in measures of lifesatisfaction and mental health [17]. Young adults and students seemed to be more severely affected by the pandemic, for instance, with regard to feelings of loneliness.

The pandemic has caused significant disruptions in the implementation of programs across educational institutions. Nursing students, being both young adults and by practical training, part of the health care system, may be particularly vulnerable during the COVID-19 pandemic [18-20]. In a Turkish study, nursing students reported increased levels of stress related to the COVID-19 pandemic [21]. A Mexican study found that nursing students and recent graduates had high levels of stress and fear, in addition to a low level of knowledge. The presence of high stress and low knowledge predicted fear regarding COVID-19 [22].

Norwegian baccalaureate nursing students have been affected by different degrees of restrictions depending on local and temporal variations in the incidence of infection. To maintain academic progress during the pandemic's lockdown periods, educational sessions have largely been converted to digital teaching. Practical training, which is normally $50 \%$ of the three-year baccalaureate nursing programme (a total of 180 European Credit Transfer System points), has proceeded with modifications. Follow-up of students during clinical practice has been implemented mainly via digital platforms. In some parts of the health care system, clinical practice has been shortened or altered to practice in simulation arenas at university campuses.

Validated and reliable tools for the assessment of an individual's fear have emerged during the COVID-19 pandemic [23-25]. Ahorsu et al. [26] developed the Fear of COVID-19 Scale (FCV-19S) with an Iranian population, which has been validated in a Norwegian sample of the general population [27]. To our knowledge, the scale has, so far, been used with a small sample of baccalaureate nursing students from the Philippines, to investigate the associations between fear of COVID-19 and the intention to quit school [28].

In this study we aimed to explore whether fear of COVID-19 is associated with self-reported general health, psychological distress and overall QoL in a sample of Norwegian baccalaureate nursing students. The use of established instruments to assess these outcomes, allowed us to compare our findings to reference data on students reported prior to the COVID-19 pandemic.

\section{Methods \\ Design and sample}

Between 27th January and 28th February, 2021, we invited all full- and part-time baccalaureate nursing students $>18$ years of age from five Norwegian universities at ten different campuses $(\mathrm{N}=6088)$ to take part in a web-based cross-sectional survey. The participating universities were Oslo Metropolitan University, Western Norway University of Applied Sciences, the University of Agder, the Norwegian University of Science and Technology and the University of Stavanger.

\section{Measures}

The survey included questions related to students' demographics, personal health and study situation during the pandemic, specifically developed for the present research by an expert group consisting of clinicians, nursing students, university staff and researchers. Additional measures included four validated instruments for assessing fear of COVID-19, overall QoL, general health and psychological distress. 
Characteristics of the respondents included age $(<25$, $25-29, \geq 30$ years), household status, study site and year of study.

COVID-19 specific questions related to personal health were developed for the present study and included the number of times the student was tested for COVID-19 (never, 1, 2, 3 or $\geq 4$ times); quarantine history (never, previous, present); feelings of loneliness due to COVID-19 (rated from 1 [strongly disagree] to 5 [strongly agree]); perceived risk for complications of COVID-19 (no, uncertain, yes); history of suspected, possible or confirmed COVID-19 infection; intention to take the vaccine (already taken, yes, undecided, no); and trust in authorities' and universities' handling of the pandemic (rated from 1 [strongly disagree] to 5 [strongly agree]).

COVID-19 specific questions related to education addressed students' perceived impact of the different aspects of their education, especially the impacts related to the conduct of clinical training and placements.

The Fear of COVID-19 Scale (FCV-19S) [26], which had been adapted and assessed for use with Norwegian samples, was used [27]. Seven items (e.g. 'I am most afraid of the coronavirus') are rated on a 5-point scale from 1 (strongly disagree) to 5 (strongly agree), with a total score ranging from 7 to 35 . Higher scores represent greater fear of COVID-19. In the present study, the average item score was used; it was calculated by dividing the total score by the number of items.

The Hopkins Symptom Checklist (SCL-5) [29] is available as a Norwegian translation [30]. It consists of five items measuring psychological distress (anxiety and depression) that are rated on a five-point scale from 1 (not at all) to 5 (extremely). The average item score was calculated by dividing the total score by the number of items answered [15]. Higher scores represent greater psychological distress.

General health was assessed using one item derived from the 36-Item Short-Form Health Survey (SF-36) [31], 'In general, would you say your health is: excellent, very good, good, fair or poor?' Responses were rated on a fivepoint scale ranging from 1 (excellent) to 5 (poor) [32]. Consistent with the SF-36 scoring algorithm, the scale was reversed scored [33]. Thus, higher scores reflect better general health, as perceived by respondents. The item was found to be as valid and reliable as multi-item scales [32].

Overall quality of life was rated on an adapted version of the Cantril Ladder, on a scale from 0 (not at all satisfied) to 10 (highly satisfied). A score of 6 or more indicates 'high life satisfaction' [34]. The question, 'All in all, how satisfied are you with your life at this time?', has been widely used in various populations and in different settings; it is considered a valid and reliable measure of overall QoL [35].

Participants' results on the FCV-19S, SCL-5 and measures of general health and overall QoL were compared to raw reference data, according to the methodology described by Hjermstad et al. [36]. At present, the FCV-19S data from the general population are unavailable. Thus, to compare the students' score on the FCV-19S we used scores from an urban adult Norwegian population $(n=1063,12.1 \%$ of the youngest (18-29 years) and 55.3\% female responders) [27]. Participants' results on SCL-5, general health and overall QoL were compared to original data from three reference populations. The mean scores for the reference populations were adjusted for sex and age and compared to our participants' results using one-sample t-tests as described by Hjermstad et al. [36]. For the SCL-5, the nursing students' scores were compared to those of Norwegian first-year medical students $(\mathrm{n}=169$, mean age 22.5 and $75 \%$ female responders) [15]. For general health our sample of nursing students was compared to the Norwegian general population reporting on an identical question covered by the SF-36 (2118, mean age 55.7 years, but the response rate of the youngest age group (18-29 years) was only $5 \%$ and $54 \%$ were female) [31] For overall QoL, reference data was available from the Norwegian Survey on Living Conditions $(\mathrm{n}=6179$, mean age $48.5 \pm 18.5$, and $49 \%$ female responders) [37].

The questionnaire was piloted with 9 nursing students, and after minor adjustments, a digital pilot study was conducted with 90 physiotherapy students. No adjustments were made after the digital pilot. A brief description of the study and an invitation to the web-based survey was e-mailed to 6088 baccalaureate nursing students' registered university e-mail addresses and made available on the respective learning portals of their teaching institution. At two universities, additional announcements were made at the students' common Facebook site. All students received at least two reminders by e-mail.

The front page of the survey contained a detailed description of the study and information about voluntary participation. By completing and submitting the survey, the students consented to participate. All responses were stored automatically in 'SurveyXact' (https://www. surveyxact.com). The respondents' IP addresses were not registered and their answers could not be linked to their identities in any way; thus, their participation was anonymous and ethical approval not required according to Norwegian legislation. The survey was evaluated by the Data Protection Officer at the responsible institution, i.e. Western Norway University of Applied Sciences, with additional approval of each university. 


\section{Statistical analyses}

Categorical variables are expressed as percentages and continuous variables as means and standard deviations (SD). The FCV-19S scores were stratified by sample characteristics, using separate one-way analysis of variance (ANOVA) tests. Differences between the sample and reference data were investigated using a one-sample t-test. Reference data, except for FCV$19 \mathrm{~S}$ scores, were adjusted to reflect the age and gender distributions of the respondents, assuming the proportion of males was similar to that of the general nursing student population (approximately 10\%). Cohen's d was used to calculate the effect sizes of the comparisons of means. Unadjusted and fully adjusted hierarchical regression analyses, with the universities as clusters, were conducted to investigate the associations between the FCV-19S score as the independent variable, and the SCL-5 general health or overall QoL score as the dependent variable in separate models. In the regression analysis we standardised the FCV-19S and the three dependent variables where the mean $=0$ and standard deviation $=1$ (dependent variables were transformed to z-scores, unstandardised regression coefficients). From the fully adjusted models, the associations between other items from the questionnaire and the SCL-5, general health and overall QoL as dependent variables were assessed and reported separately if they had meaningful effect sizes, as assessed by Cohen's d. A meaningful Cohen's d was judged to be a difference $\geq 0.2 \mathrm{SD}$ of the dependent variable per $2 \mathrm{SD}$ changes in the FCV-19S or between respondents representing the lower or higher end of the discrete variables with $2-5$ categories $[38,39]$.

Overall, the effect sizes were interpreted as follows: trivial $(<0.2)$, small $(0.2$ to $<0.5)$, moderate $(0.5$ to $<0.8)$ and large $(\geq 0.8)[40]$. We reported two-tailed P-values and $95 \%$ confidence intervals $(\mathrm{CI})$ as continuous indicators of the robustness of the estimates. Survey data were downloaded to Microsoft ${ }^{\circledR}$ Excel $^{\circledR}$, manually coded, and then transferred to IBM SPSS (Statistics for Windows, Version 27.0. Armonk, NY: IBM Corp) for the statistical analyses.

\section{Results}

In total, 2605 of the 6088 students responded to the survey, yielding a response rate of $43 \%$, differing between the universities from 21 to $50 \%$. Among these, $41 \%$ $(\mathrm{n}=1077), 31 \%(\mathrm{n}=801)$ and $28 \%(\mathrm{n}=730)$ were baccalaureate students in their programmes' first, second and third years, respectively. For the seven items in the FCV19S, Cronbach's alpha was 0.87 (ranging from 0.84 to 0.86 if single items were deleted), and for the five items in the
SCL-5, Cronbach's alpha was 0.88 (ranging from 0.84 to 0.87 if single items were deleted).

\section{Fear of COVID-19 Scale}

Sample characteristics and mean FCV-19S scores are presented in Table 1. The mean FCV-19S score of our sample of nursing students was $2.45 \pm 0.8$, compared to 1.85 in the reference population [27]. This difference was statistically significant $(P<0.001)$ with a moderate effect size (Cohen's $d=0.75)$ (Table 2).

Compared to the gender- and age-adjusted reference data, the nursing students' data showed significantly worse scores on general health, psychological distress and overall QoL (Table 2, Fig. 1). In terms of effect size, the difference was trivial for general health, moderate for psychological distress (SCL-5) and large for overall QoL (Additional file 1).

Eight out of twelve background variables were significantly associated with fear of COVID-19: year in nursing school, younger age, being at risk for COVID-19 complications, lower trust in the government's and universities' handling of the pandemic, feeling lonely due to COVID19 and not being in clinical practice during the pandemic. Fear of COVID-19 differed significantly among the universities.

\section{General health}

Fear of COVID-19 was significantly associated with general health in the adjusted analysis, with a small effect size of $-0.26 \mathrm{SD}$ difference in general health associated with a 2 SD increase in the FCV-19S score (Table 3).

Other variables from the fully adjusted analysis that were significantly associated with general health and had a meaningful effect size were: being at risk for COVID19 complications (yes versus no [reference]: standardised score $=-0.77$ [95\% CI $-0.91,-0.63]$ ), feelings of loneliness (highest level versus lowest [reference]: standardised score $=-0.48[95 \% \mathrm{CI}-0.64,-0.31])$ and level of trust in the government (lowest versus highest [reference]: standardised score $=-0.37$ [95\% CI $-0.52,-0.22]$ ) (Additional file 1: Table 1).

\section{Psychological distress}

Fear of COVID-19 was significantly associated with psychological distress in the adjusted analysis, with a moderate effect size of 0.76 SD difference in the SCL- 5 per 2 SD increase in the FCV-19S score (Table 3).

Other variables from the fully adjusted model that were significantly associated with psychological distress and had a meaningful effect size were: age $(<25$ years old versus $\geq 30$ years [reference]: standardised score $=0.24[95 \%$ CI $-0.15,0.33]$ ), feelings of loneliness (highest level versus lowest [reference]: standardised score $=1.01[95 \% \mathrm{CI}$ 
Table 1 Baccalaureate nursing students' characteristics and level of fear of COVID-19 $(N=2605)$

\begin{tabular}{|c|c|c|c|c|}
\hline & $\begin{array}{l}\text { Number of } \\
\text { respondents }\end{array}$ & $\begin{array}{l}\text { Percent } \\
\text { respondents }\end{array}$ & Mean FCV-19S $\pm S D^{b}$ & $P$ value ${ }^{a}$ \\
\hline University A ( $n=1893$ ) & & & & $<0.001$ \\
\hline$B(n=1796)$ & 938 & 36 & $2.57 \pm 0.85$ & \\
\hline$C(n=858)$ & 874 & 34 & $2.41 \pm 0.79$ & \\
\hline$D(n=675)$ & 396 & 15 & $2.32 \pm 0.71$ & \\
\hline \multirow[t]{2}{*}{$E(n=866)$} & 214 & 8 & $2.38 \pm 0.72$ & \\
\hline & 184 & 7 & $2.44 \pm 0.80$ & \\
\hline Years in the baccalaureate nursing programme & & & & $<0.001$ \\
\hline 1 & 1074 & 41 & $2.54 \pm 0.82$ & \\
\hline 2 & 801 & 31 & $2.40 \pm 0.81$ & \\
\hline 3 & 730 & 28 & $2.45 \pm 0.80$ & \\
\hline Age, years & & & & $<0.001$ \\
\hline$<25$ & 1846 & 71 & $2.50 \pm 0.80$ & \\
\hline $25-29$ & 377 & 14 & $2.37 \pm 0.82$ & \\
\hline$\geq 30$ & 382 & 15 & $2.27 \pm 0.74$ & \\
\hline Living alone & & & & 0.663 \\
\hline No & 2140 & 82 & $2.45 \pm 0.80$ & \\
\hline Yes & 465 & 18 & $2.47 \pm 0.80$ & \\
\hline Number of times tested for COVID-19 & & & & 0.589 \\
\hline Never & 765 & 29 & $2.44 \pm 0.81$ & \\
\hline 1 & 724 & 28 & $2.43 \pm 0.80$ & \\
\hline 2 & 445 & 17 & $2.43 \pm 0.81$ & \\
\hline 3 & 325 & 12 & $2.47 \pm 0.81$ & \\
\hline$\geq 4$ & 346 & 13 & $2.51 \pm 0.77$ & \\
\hline History of a positive COVID-19 test & & & & 0.077 \\
\hline No & 2482 & 95 & $2.45 \pm 0.80$ & \\
\hline Yes & 110 & 5 & $2.57 \pm 0.82$ & \\
\hline Quarantine status related to COVID-19 & & & & 0.145 \\
\hline Never & 1302 & 50 & $2.42 \pm 0.80$ & \\
\hline Previous & 1253 & 48 & $2.48 \pm 0.80$ & \\
\hline Now & 150 & 2 & $2.56 \pm 0.91$ & \\
\hline At risk for COVID-19 complications & & & & $<0.001$ \\
\hline No & 2091 & 80 & $2.36 \pm 0.76$ & \\
\hline Uncertain & 324 & 13 & $2.80 \pm 0.82$ & \\
\hline Yes & 190 & 7 & $2.81 \pm 0.95$ & \\
\hline Trust in the government's handling of the COVID-19 situation & & & & $<0.001$ \\
\hline Strongly disagree/disagree & 232 & 9 & $2.56 \pm 0.97$ & \\
\hline Neither disagree nor agree & 561 & 22 & $2.53 \pm 0.82$ & \\
\hline Agree & 1344 & 52 & $2.45 \pm 0.79$ & \\
\hline Strongly agree & 468 & 18 & $2.30 \pm 0.80$ & \\
\hline Trust in the universities' handling of the COVID-19 situation & & & & $<0.001$ \\
\hline Strongly disagree & 182 & 7 & $2.60 \pm 0.96$ & \\
\hline Disagree & 447 & 17 & $2.51 \pm 0.85$ & \\
\hline Neither disagree nor agree & 783 & 30 & $2.53 \pm 0.80$ & \\
\hline Agree & 984 & 38 & $2.36 \pm 0.82$ & \\
\hline Strongly agree & 213 & 8 & $2.29 \pm 0.80$ & \\
\hline Feeling lonely due to COVID-19 & & & & $<0.001$ \\
\hline Strongly disagree & 165 & 6 & $1.94 \pm 0.70$ & \\
\hline Disagree & 380 & 15 & $2.18 \pm 0.72$ & \\
\hline Neither disagree nor agree & 446 & 17 & $2.29 \pm 0.71$ & \\
\hline
\end{tabular}


Table 1 (continued)

\begin{tabular}{llll}
\hline & $\begin{array}{l}\text { Number of } \\
\text { respondents }\end{array}$ & $\begin{array}{l}\text { Percent } \\
\text { respondents }\end{array}$ & ${\text { Mean FCV-19S } \pm \mathbf{S D}^{\mathbf{b}}}^{P_{\text {value }}}$ \\
\hline Agree & 899 & 34 & $2.45 \pm 0.74$ \\
$\quad$ Strongly agree & 718 & 28 & $2.81 \pm 0.84$ \\
Engagement in clinical practice during the pandemic & & 61 & $2.41 \pm 0.79$ \\
$\quad$ Yes & 1591 & 39 & $2.52 \pm 0.80$ \\
No & 1014 & $<0.001$ \\
\hline
\end{tabular}

FCV-19S: Fear of Covid-19 Scale. Higher score on Fear of COVID-19 scale (FCV-19S) (1-5) reflects greater fear of COVID-19. University A: Oslo Metropolitan University, B: Western Norway University of Applied Sciences, C: University of Agder, D: Norwegian University of Sciences and Technology, E: University of Stavanger

a Unadjusted $P$ values for between-groups differences (one way ANOVA)

b Standard deviation

Table 2 Self-reported fear of COVID-19, general health, psychological distress and overall quality of life in bachelor nursing students versus reference data

\begin{tabular}{|c|c|c|c|c|}
\hline Variables & Sample, mean \pm SD & Population, mean ${ }^{c}$ & Cohen's d $\left(95 \% \mathrm{Cl}^{\mathrm{b}}\right)$ & $P$ value* \\
\hline FCV-19S ${ }^{a, g}(1-5)$ & $2.45 \pm 0.80$ & 1.85 & $0.80(0.70,0.79)$ & $<0.001$ \\
\hline General health $^{\mathrm{d}}(1-5)$ & $3.50 \pm 0.93$ & 3.57 & $-0.07(-0,11,-0.03)$ & $<0.001$ \\
\hline Psychological distress $(S C L-5)^{e}(1-5)$ & $2.68 \pm 1.03$ & 2.12 & $0.55(0.51,0.59)$ & $<0.001$ \\
\hline Overall Quality of life ${ }^{f}(0-10)$ & $5.50 \pm 2.16$ & 8.00 & $-1.16(-1.21,-1.11)$ & $<0.001$ \\
\hline
\end{tabular}

${ }^{a}$ One-sample t-test mean sample score and unadjusted norm score FCV-19S (Iversen et al. 2021)

${ }^{\mathrm{b}}$ Confidence interval

${ }^{c}$ Adjusted for age and gender

*One sample student's t-test

${ }^{d}$ In line with the SF-36 scoring algorithm, the item was reversed. Higher score reflects better perceived general health

${ }^{e}$ Higher score on Hopkins Symptom Checklist (SCL-5) reflect more psychological distress

${ }^{f}$ Higher score of overall quality of health reflect better perceived overall quality of life

${ }^{g}$ Higher score of FCV-19S reflect higher level of fear of COVID-19

$0,87,1.15]$ ) and level of trust in the government (lowest versus highest [reference]: standardised score $=0.28[95 \%$ CI 0.15, 0.41] (Additional file 1: Table 2).

\section{Overall quality of life}

Fear of COVID-19 was significantly associated with overall QoL in the adjusted analysis, but with a trivial effect size of -0.18 SD difference in overall QoL per $2 \mathrm{SD}$ increase in the FCV-19S score (Table 3).

Other variables significantly associated with overall QoL, and with a meaningful effect size, were feelings of loneliness (highest level versus lowest [reference]: standardised score $=-1.38[95 \%$ CI $-0.52,-1.23]$ ) and level of trust in the government's handling of the pandemic (lowest level versus highest [reference]: standardised score $=-0.29[95 \%$ CI $-0.43,-0.15]$ ) (Additional file 1: Table 3).

\section{Discussion}

In our survey, Norwegian baccalaureate nursing students reported significantly higher levels of fear of COVID-19 compared to urban Norwegian adults [27]. Our mean FCV-19S score of 2.45 is, however, lower than the mean score of 2.95 , reported previously for Filipino nursing students [28]. Two similar studies, one in Spanish University students (12\% nursing students) [41], and one in Russian/Belarussian young adults (28\% university students) [42] reported levels of FCV-19S of 2.4 and 2.45 , respectively, comparable to our findings in Norwegian nursing students.

Eight out of twelve background variables were significantly associated with fear of COVID-19 in the baccalaureate nursing students. Fear of COVID-19 was more evident among first year nursing students, students under the age of 25 and students who did not trust the government's or the universities' handling of the COVID-19 situation. Fear of COVID-19 was also more prominent among students who reported feeling lonely due to COVID-19 and among those who had not been 

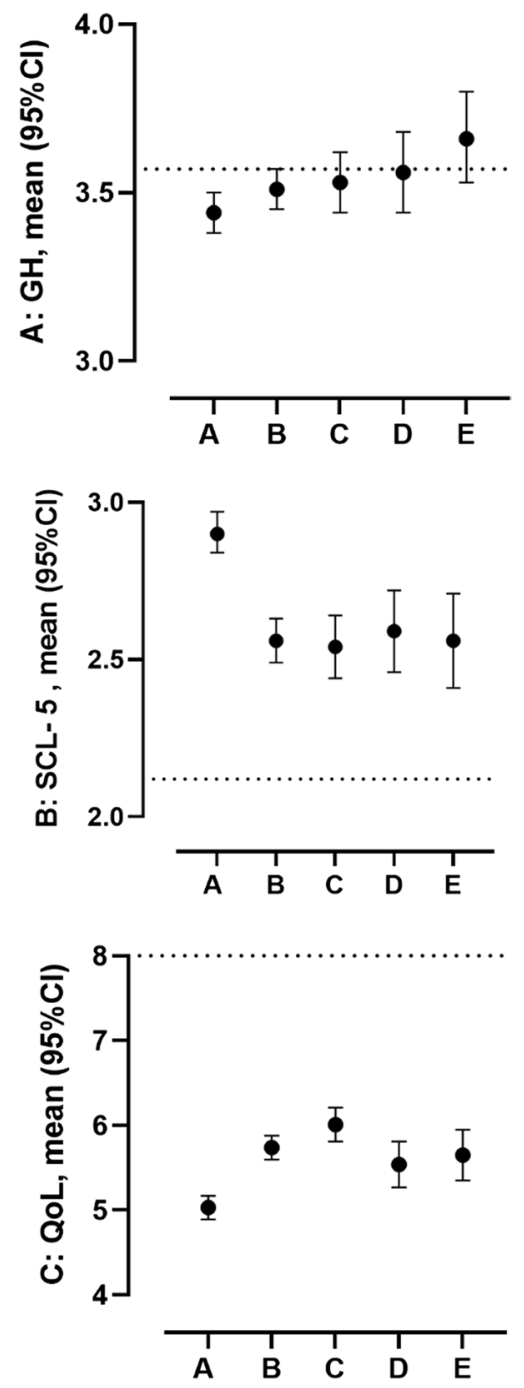

Fig. 1 a Mean and $95 \% \mathrm{Cl}$ scores of general health $(\mathrm{GH})$ ranging from 1 (worst) to 5 (best). (Originally scored from 1 (excellent) to 5 (poor), but in line with the SF-36 scoring algorithm, the item was reversed so higher scores reflect better perceived general health). b Psychological distress (SCL-5) ranging from 1 (best) to 5 (worst) and, c Overall quality of life (QoL) ranging from 0 (worst) to 10 (best) stratified by university clusters $(n=5)$. University A: Oslo Metropolitan University, B: Western Norway University of Applied Sciences, C: University of Agder, D: Norwegian University of Sciences and Technology, E: University of Stavanger. Dashed lines in the respective figures represent the age and gender adjusted reference data scores

in clinical practice. Interestingly, higher health literacy was associated with lower FCV-19S scores in a cross sectional study of medical students in Vietnam [43].

Our findings are consistent with the results of several other studies of different psychological outcomes, such as anxiety, fear and stress in nursing students during the present pandemic in different countries $[13,17,19,20]$.
Table 3 Hierarchical regression analysis showing associations between fear of COVID-19 (independent variable) and general health, psychological distress and quality of life (dependent variables)

\begin{tabular}{|c|c|c|}
\hline Models & $\begin{array}{l}\text { Standardized } \\
\text { coefficient }\left(95 \% \mathrm{Cl}^{\mathrm{a}}\right)\end{array}$ & $P$ value \\
\hline \multicolumn{3}{|l|}{ General health } \\
\hline FCV-19S: Unadjusted estimate & $-0.23(-0.27,-0.20)$ & $<0.001$ \\
\hline FCV-19S: Adjusted estimate & $-0.13(-0.17,-0.09)$ & $<0.001$ \\
\hline \multicolumn{3}{|l|}{ Psychological distress (SCL-5) } \\
\hline FCV-19S: Unadjusted estimate & $0.51(0.47,0.54)$ & $<0.001$ \\
\hline FCV-19S: Adjusted estimate & $0.38(0.34,0.41)$ & $<0.001$ \\
\hline \multicolumn{3}{|l|}{ Overall quality of life } \\
\hline FCV-19S: Unadjusted estimate & $-0.27(-0.30,-0.23)$ & $<0.001$ \\
\hline FCV-19S: Adjusted estimate & $-0.09(-0.13,-0.06)$ & $<0.001$ \\
\hline
\end{tabular}

FCV-19S: Fear of COVID-19 scale. Psychological distress as measured by the SCL-5: The five item Hopkins symptom checklist. Cluster effects are accounted for in the unadjusted analysis, while the adjusted analyses are adjusted for years in nursing school, age, living alone or not, times tested for COVID-19, history of a positive COVID-19 test, quarantine status related to COVID-19, at risk for COVID19 complications or not, level of trust in governmental handling of the COVID-19 situation, level of trust in universities' handling of the COVID-19 situation, feeling of loneliness due to COVID-19 and whether or not the student has engaged in clinical practice during the pandemic. All dependent variables have been transformed to z-scores. Unstandardized regression coefficients

${ }^{a} \mathrm{Cl}$ confidence interval

An important aspect is that the timely and strict national and regional measures have contributed to keeping the spread of COVID-19 low in Norway, as compared to other European countries [44]. Collectively, the results indicate that students who are young, lonely and less socially interactive than their peers are the most vulnerable individuals. A recently published systematic review of the effects of COVID-19 on psychological outcomes of the general population showed that the risk factors associated with distress measures included female gender, younger age group ( $\leq 40$ years), presence of a chronic/psychiatric illness, student status and frequent exposure to social media/news concerning COVID-19 [45].

Baccalaureate nursing students had significantly worse scores on general health, psychological distress and overall QoL than did the gender- and age-adjusted reference data collected prior to the COVID-19 epidemic. However, the associations of the FCV-19S score with general health, psychological distress and overall QoL were small, moderate and trivial, respectively. The weak association between fear of COVID-19 and overall QoL indicates that other factors related to being a student during a pandemic may have larger effects. For example, a Polish study found that social distancing, self-isolation and limited access to public spaces among young university students were associated with decreased QoL [46]. Moreover, a 
study of nursing students in rural Appalachia, West Virginia, USA, suggested that factors such as resilience and preparedness for online learning were associated with QoL [47].

The pandemic caused significant disruptions in the daily lives of baccalaureate nursing students. First year students had to encounter a new reality just a few months after having established life as a student. All students were exposed to stressful factors, such as the closing of campuses and conversion of educational sessions to digital teaching. Some may have experienced cancellations of planned practical training, while others, by practical training, became part of the health care system where the pandemic led to an increased workload due to restrictions, frequent testing and an increased number of patients. In sum, such factors may have added to the students' perceived fear. Fear is considered an adaptive normal response in the presence of danger or uncertainty but it can become burdensome if the threat is continuous and unpredictable [10], as in the current COVID19 pandemic. Not knowing how long the pandemic will last, what consequences it may have for their personal health, progression in their studies and future working life probably raises students' fear and concerns. However, knowledge and skills regarding infection control measures, a stable educational framework and continuing contact with the university staff through high quality distant teaching may support students during a challenging period [14].

The level of fear of COVID-19 between universities seemed to vary with the regional incidence of infection and level and duration of restrictions during the period in which the survey was conducted. Apart from their fear of Covid-19 scores, students in the capital area (attending Oslo Metropolitan University) also reported significantly higher levels of psychological distress (SCL-5) and worse overall QoL compared to those in the other universities (Fig. 1). This finding is consistent with studies of distress among Norwegian students in December 2020, revealing higher levels of psychological distress in the two largest cities where societal restrictions were most intrusive[17]. A study conducted in China among nurses and nursing students reported higher scores on measures of anxiety and anger in participants living in proximity to COVID19 zones, i.e. areas with a higher prevalence of infection [13].

The emergence of the COVID-19 pandemic and its consequences can probably explain the absolute difference in scores between the baccalaureate nursing students and reference data. Most notably, QoL was reduced by $1.16 \mathrm{SDs}$ (Table 2), which is interpreted as a large effect size. The level of psychological distress was significantly higher in our sample than in the pre-pandemic reference data reported by medical students [15], while general health was not as affected. The latter observation may be interpreted as general health being more of a physical measure, whereas fear in general, is more strongly associated with psychological distress. Our findings correspond to a recently published meta-analysis which reported an association of fear of COVID-19 with a wide range of mental health problems in the general population [5]. Experiences from previous pandemics, such as the MERS-CoV pandemic, indicate that higher education institutions (with health programmes) need to educate their students about effective crisis management and provide high quality and safe clinical learning environments [48]. Inadequate efforts to recognise and address college students' mental health challenges, especially during a pandemic, could have long-term consequences on their health and education [48].

\section{Strengths and limitations of this study}

This cross-sectional survey design is a limitation, as no changes over time, either from before or until the end of the pandemic, can be assessed. Nevertheless, the sample size $(n=2605)$, fairly high response rate and comparisons of students with reference data increases the reliability of our findings.

We used validated instruments for the subjective reporting of health and overall QoL, which support the quality of sufficient data. The data may help guide the balancing of infection control measures at higher education institutions during a pandemic, while at the same time protecting students' needs. Large scale and longitudinal follow up studies are warranted.

\section{Study implications and conclusion}

Research on baccalaureate nursing students' subjective perceptions of health and overall QoL helped identify factors that may represent a threat to individual students. Self-reported data can have an important cognitive and practical value, and may contribute to the handling of ongoing and future pandemics [48]. To reduce fear and psychological distress, and to improve QoL among nursing students during a pandemic, closer follow-up of vulnerable students could be implemented by the universities. Our results indicate that special attention should be given to first year students, students reporting to feel lonely, students not engaged in clinical practice and those who report a low level of trust.

The Norwegian version of the FCV-19S [27] has been used to investigate the associations of fear of COVID19 with self-reported health measures and QoL in nursing students. Compared to the reference data collected prior to the COVID-19 outbreak, our respondents 
reported significantly worse general health and overall QoL, and greater psychological distress. These differences were trivial for general health, moderate for psychological distress and large for QoL. The large difference in QoL between the nursing students who responded and the reference data was only slightly related to fear of COVID-19 scores, indicating that other factors, possibly related to being a student during a pandemic, might have contributed to the results. This possibility will be explored in future studies.

\section{Supplementary Information}

The online version contains supplementary material available at https://doi. org/10.1186/s12955-021-01837-2.

Additional file 1: Table 1. Multiple hierarchical regression analysis with general health (z-score) as the dependent variable. Table 2. Multiple hierarchical regression analysis with psychological distress (SCL-5 z-score) as the dependent variable. Table 3. Multiple hierarchical regression analysis with overall quality of life (z-score) as the dependent variable.

\section{Acknowledgements}

Not applicable.

\section{Authors' contributions}

All authors contributed to the study conception and design. Materials preparation, data collection and analysis were performed by EGB, KHG, JRA, OB, BB, $\mathrm{KH}, \mathrm{IHHH}, \mathrm{MMI}, \mathrm{BL}, \mathrm{TMN}, \mathrm{KR}, \mathrm{GR}, \mathrm{KHU}$, IU and TNF. The first draft of the manuscript was written by $E G B$, and all authors commented on previous versions of the manuscript. All authors read and approved the final manuscript.

\section{Funding}

This research received no external funding.

\section{Availability of data and materials}

The dataset analysed during the current study are available from the corresponding author on reasonable request.

\section{Declarations}

\section{Ethics approval and consent to participate}

All procedures performed in studies involving human participants were in accordance with the ethical standards of the institutional and/or national research committee and with the 1964 Helsinki Declaration and its later amendments or comparable ethical standards. Informed consent was obtained from all individual participants included in the study.

\section{Consent for publication}

Not applicable.

\section{Competing interests}

All authors confirm no actual or potential conflicts of interest.

\footnotetext{
Author details

${ }^{1}$ Department of Health and Caring Sciences, Western Norway University of Applied Sciences, Inndalsveien 28, 5063 Kronstad, Bergen, Norway. ${ }^{2}$ Department of Public Health and Nursing, Norwegian University of Science and Technology, NTNU, 7491 Trondheim, Norway. ${ }^{3}$ Department of Quality and Health Technology, University of Stavanger, Kjell Arholms gate 41, 4021 Stavanger, Norway. ${ }^{4}$ Department of Health and Nursing Sciences, University of Agder, P.O Box 422, 4604 Kristiansand, Norway. ${ }^{5}$ Department of Nursing and Health Promotion, Oslo Metropolitan University, St. Olavs plass, P.O. Box 4, 0130 Oslo, Norway. ${ }^{6}$ Department of Physiotherapy, Oslo Metropolitan University, St.
}

Olavs plass, P.O. Box 4, 0130 Oslo, Norway. ${ }^{7}$ Department of Surgery, Voss Hospital, Haukeland University Hospital/The Western Norway Health Region Authority, Sjukehusvegen 16, 5704 Voss, Norway. ${ }^{8}$ Department of Cardiology and Department of Cardiothoracic Surgery, St. Olav Hospital, Trondheim University Hospital, Postbox 3250, 7006 Torgarden, Trondheim, Norway. ${ }^{9}$ Department of Heart Disease, Haukeland University Hospital, Jonas Lies vei 65, 5021 Bergen, Norway. ${ }^{10}$ Department of Clinical Research, SSHF, P.O. Box 416, 4604 Kristiansand, Norway. ${ }^{11}$ Førde Hospital Trust, Post Office Box 1000, 6807 Førde, Norway.

Received: 12 May 2021 Accepted: 6 August 2021

Published online: 19 August 2021

\section{References}

1. Bryson WJ. Long-term health-related quality of life concerns related to the COVID-19 pandemic: a call to action. Qual Life Res. 2021;30:643-5.

2. Solomou I, Constantinidou F. Prevalence and predictors of anxiety and depression symptoms during the COVID-19 pandemic and compliance with precautionary measures: age and sex matter. Int J Environ Res Public Health. 2020;17:4924.

3. Epifanio MS, Andrei F, Mancini G, Agostini F, Piombo MA, Spicuzza V, Riolo M, Lavanco G, Trombini E, La Grutta S. The impact of COVID-19 pandemic and lockdown measures on quality of life among Italian general population. J Clin Med. 2021;10:289.

4. Wong AW, Shah AS, Johnston JC, Carlsten C, Ryerson CJ. Patient-reported outcome measures after COVID-19: a prospective cohort study. Eur Respir J. 2020:56:2003276.

5. Al Maqbali M, Al Sinani M, Al-Lenjawi B. Prevalence of stress, depression, anxiety and sleep disturbance among nurses during the COVID-19 pandemic: a systematic review and meta-analysis. J Psychosomat Res. 2020;2020:110343.

6. Trumello C, Bramanti SM, Ballarotto G, Candelori C, Cerniglia L, Cimino S, Crudele M, Lombardi L, Pignataro S, Viceconti ML, Babore A. Psychological adjustment of healthcare workers in Italy during the COVID-19 pandemic: differences in stress, anxiety, depression, burnout, secondary trauma, and compassion satisfaction between frontline and non-frontline professionals. Int J Environ Res Public Health. 2020;17:8358.

7. Stojanov J, Malobabic M, Stanojevic G, Stevic M, Milosevic V, Stojanov A. Quality of sleep and health-related quality of life among health care professionals treating patients with coronavirus disease-19. Int J Soc Psychiatry. 2020;2020:20764020942800.

8. Group W. The World Health Organization quality of life assessment (WHOQOL): position paper from the World Health Organization. Soc Sci Med. 1995:41:1403-9.

9. NOKUT National Student Survey 2020. https://www.studiebarometeret. no/en/.

10. Kaparounaki CK, Patsali ME, Mousa DV, Papadopoulou EVK, Papadopoulou KKK, Fountoulakis KN. University students' mental health amidst the COVID-19 quarantine in Greece. Psychiatry Res. 2020;290:113111.

11. Viner RM, Russell SJ, Croker H, Packer J, Ward J, Stansfield C, Mytton O, Bonell C, Booy R. School closure and management practices during coronavirus outbreaks including COVID-19: a rapid systematic review. Lancet Child Adolesc Health. 2020;4:397-404.

12. Sakib N, Akter T, Zohra F, Bhuiyan Al, Mamun MA, Griffiths MD. Fear of COVID-19 and depression: a comparative study among the general population and healthcare professionals during COVID-19 pandemic crisis in Bangladesh. Int J Ment Health Addict. 2021;2021:1-17.

13. Huang L, Lei W, Xu F, Liu H, Yu L. Emotional responses and coping strategies in nurses and nursing students during Covid-19 outbreak: a comparative study. PLoS ONE. 2020;15:e0237303.

14. Savitsky B, Findling Y, Ereli A, Hendel T. Anxiety and coping strategies among nursing students during the covid-19 pandemic. Nurse Educ Pract. 2020;46:102809.

15. Ruud N, Lovseth LT, Isaksson Ro K, Tyssen R. Comparing mental distress and help-seeking among first-year medical students in Norway: results of two cross-sectional surveys 20 years apart. BMJ Open. 2020;10:e036968.

16. Knapstad M, Sivertsen B, Knudsen AK, Smith ORF, Aaro LE, Lonning KJ, Skogen JC. Trends in self-reported psychological distress among college and university students from 2010 to 2018. Psychol Med. 2021;51:470-8. 
17. Quality of life and mental health during the COVID-19 pandemic November-December 2020. https://www.fhi.no/div/helseundersokelser/ fylkeshelseundersokelser/livskvalitet-og-psykisk-helse-under-koronaepid emien--nov-des-2020/.

18. Leigh J, Bolton M, Cain K, Harrison N, Bolton NY, Ratcliffe S. Student experiences of nursing on the front line during the COVID-19 pandemic. $\mathrm{Br} J$ Nurs. 2020;29:788-9.

19. Lovrić R, Farčić N, Mikšić Š, Včev A. Studying during the COVID-19 pandemic: a qualitative inductive content analysis of nursing students' perceptions and experiences. Educ Sci. 2020;10:188.

20. Gallego-Gomez JI, Campillo-Cano M, Carrion-Martinez A, Balanza S, Rodriguez-Gonzalez-Moro MT, Simonelli-Munoz AJ, Rivera-Caravaca JM. The COVID-19 pandemic and its impact on homebound nursing students. Int J Environ Res Public Health. 2020;17:7383.

21. Aslan H, Pekince H. Nursing students' views on the COVID-19 pandemic and their percieved stress levels. Perspect Psychiatr Care. 2021;57:695-701.

22. Medina Fernandez IA, Carreno Moreno S, Chaparro Diaz L, GallegosTorres RM, Medina Fernandez JA, Hernandez Martinez EK. Fear, stress, and knowledge regarding COVID-19 in nursing students and recent graduates in Mexico. Invest Educ Enferm. 2021;39:e05.

23. Mertens G, Gerritsen L, Duijndam S, Salemink E, Engelhard IM. Fear of the coronavirus (COVID-19): predictors in an online study conducted in March 2020. J Anxiety Disord. 2020;74:102258.

24. Taylor S, Landry CA, Paluszek MM, Fergus TA, McKay D, Asmundson GJG. Development and initial validation of the COVID Stress Scales. J Anxiety Disord. 2020;72:102232.

25. Lee SA. Coronavirus Anxiety Scale: a brief mental health screener for COVID-19 related anxiety. Death Stud. 2020;44:393-401.

26. Ahorsu DK, Lin CY, Imani V, Saffari M, Griffiths MD, Pakpour AH. The fear of COVID-19 scale: development and initial validation. Int J Ment Health Addict. 2020;2020:1-9.

27. Iversen MM, Norekval TM, Oterhals K, Fadnes LT, Maeland S, Pakpour AH, Breivik K. Psychometric properties of the Norwegian version of the fear of COVID-19 scale. Int J Ment Health Addict. 2021. https://doi.org/10.1007/ s11469-020-00454-2.

28. De Los Santos JAA, Labrague LJ, Falguera CC. Fear of COVID-19, poor quality of sleep, irritability, and intention to quit school among nursing students: a cross-sectional study. Perspect Psychiatr Care. 2021. https:// doi.org/10.1111/ppc.12781.

29. Schmalbach B, Zenger M, Tibubos AN, Kliem S, Petrowski K, Brahler E. Psychometric properties of two brief versions of the hopkins symptom checklist: HSCL-5 and HSCL-10. Assessment. 2021;28:617-31.

30. Strand BH, Dalgard OS, Tambs K, Rognerud M. Measuring the mental health status of the Norwegian population: a comparison of the instruments SCL-25, SCL-10, SCL-5 and MHI-5 (SF-36). Nord J Psychiatry. 2003;57:113-8

31. Jacobsen EL, Bye A, Aass N, Fossa SD, Grotmol KS, Kaasa S, Loge JH, Moum T, Hjermstad MJ. Norwegian reference values for the Short-Form Health Survey 36: development over time. Qual Life Res. 2018;27:1201-12.

32. Macias C, Gold PB, Ongur D, Cohen BM, Panch T. Are single-item global ratings useful for assessing health status? J Clin Psychol Med Settings. 2015:22:251-64.
33. Ware J, Kosinski M, Keller S. SF-36 physical and mental health summary scales. A user's manual 2001:1994.

34. Cantril H. The Pattern of human concerns. New Brunswick: Rutgers University Press; 1966.

35. Levin KA, Currie C. Reliability and validity of an adapted version of the Cantril Ladder for use with adolescent samples. Soc Indic Res. 2014;119:1047-63.

36. Hjermstad MJ, Fayers PM, Bjordal K, Kaasa S. Using reference data on quality of life - the importance of adjusting for age and gender, exemplified by the EORTC QLQ-C30 (+3). Eur J Cancer. 1998;34:1381-9.

37. Norwegian Surveys on Living Conditions EU-SILC, 2018. https://www.nsd. no/nsddata/serier/levekaarundersokelser.html.

38. Gelman A, Park DK. Splitting a predictor at the upper quarter or third and the lower quarter or third. Am Stat. 2009;63:1-8.

39. Gelman A. Scaling regression inputs by dividing by two standard deviations. Stat Med. 2008;27:2865-73.

40. Cohen J. Statistical power analysis for the behavioral sciences. Boca Raton: Academic Press; 2013.

41. Martínez-Lorca M, Martínez-Lorca A, Criado-Álvarez JJ, Armesilla MDC, Latorre JM. The fear of COVID-19 scale: validation in Spanish University students. Psychiatry Res. 2020;293:113350.

42. Reznik A, Gritsenko V, Konstantinov V, Khamenka N, Isralowitz R. COVID-19 Fear in Eastern Europe: validation of the fear of COVID-19 scale. Int J Ment Health Addic. 2020. https://doi.org/10.1007/s11469-020-00283-3

43. Nguyen HT, Do BN, Pham KM, Kim GB, Dam HT, Nguyen TT, Nguyen TT, Nguyen YH, Sørensen K, Pleasant A. Fear of COVID-19 scale-associations of its scores with health literacy and health-related behaviors among medical students. Int J Environ Res Public Health. 2020;17:4164.

44. Graphs and maps week 14, 2021. https://www.euromomo.eu/ graphs-and-maps.

45. Xiong J, Lipsitz O, Nasri F, Lui LMW, Gill H, Phan L, Chen-Li D, lacobucci M, Ho R, Majeed A, McIntyre RS. Impact of COVID-19 pandemic on mental health in the general population: a systematic review. J Affect Disord. 2020;277:55-64.

46. Szczepańska A, Pietrzyka K. The COVID-19 epidemic in Poland and its influence on the quality of life of university students (young adults) in the context of restricted access to public spaces. Z Gesundh Wiss. 2021;2021:1-11.

47. Keener TA, Hall K, Wang K, Hulsey T, Piamjariyakul U. Quality of life, resilience, and related factors of nursing students during the COVID-19 pandemic. Nurse Educ. 2021;46:143-8.

48. Browning MH, Larson LR, Sharaievska I, Rigolon A, McAnirlin O, Mullenbach L, Cloutier S, Vu TM, Thomsen J, Reigner N. Psychological impacts from COVID-19 among university students: risk factors across seven states in the United States. PLoS ONE. 2021;16:e0245327.

\section{Publisher's Note}

Springer Nature remains neutral with regard to jurisdictional claims in published maps and institutional affiliations.

\footnotetext{
Ready to submit your research? Choose BMC and benefit from:

- fast, convenient online submission

- thorough peer review by experienced researchers in your field

- rapid publication on acceptance

- support for research data, including large and complex data types

- gold Open Access which fosters wider collaboration and increased citations

- maximum visibility for your research: over $100 \mathrm{M}$ website views per year
}

At BMC, research is always in progress.

Learn more biomedcentral.com/submissions 